\title{
Biomimatic formation of disordered dolomite and its impliaction
}

\author{
GEN-TAO ZHOU ${ }^{1}$, YA-RONG HUANG ${ }^{1}$, HAN LI ${ }^{1}$, QI-ZHI \\ $\mathrm{YAO}^{2}$ \\ ${ }^{1}$ School of Earth and Space Sciences, University of Science \\ and Technology of China, Hefei,230026. \\ gtzhou@ustc.edu.cn \\ ${ }^{2}$ School of Chemistry and Materials Science, University of \\ Science and Technology of China, Hefei, 230026.
}

Dolomite is much more abundant in geological records than in modern sediments, and many efforts have also been unsuccessful to inorganically synthesize dolomite under ambient conditions. Therefore, the origin and mechanism of the low-temperature dolomite have long been an enigma, and referred to as the "dolomite problem". In recent decades, some studies ascertained that microbes play a dominant role in low-temperature dolomite formation, and proposed that the microbial metabolism can create the favorable chemical environments for dolomite precipitation. However, the studies involving field observations unveiled that dolomite can be also found within metabolically non-intensive and inactive microbial mats buried in sediments. It appears that besides the microbial metabolic activity, the microbial biomass without biological activity likely also exert a crucial control over dolomite formation. In this context, different bacterial components were first isolated from bacterial cultures, and then used to influence $\mathrm{Ca}-\mathrm{Mg}$ carbonate mineralization under biomimetic conditions. Our results show that the presence of bacterial cells facilitates the formation of disordered dolomite. Further mineralization experiments with bare cells and bound extracellular polymeric substances (BEPS) isolated from the bacterial cells reveals that the bare cells and BESP can all lead to the disordered dolomite, and such promotion can be attributed to high concentration and density of carboxyl and phosphoryl groups on the bacterial bare cells and bound EPS. Hence, it can follow that bacterial biomass without active microbial activities can also play an important role in the formation of dolomite. Current results can not only extend the insight into the biologically influenced mineralization of Ca$\mathrm{Mg}$ carbonates, but also shed light on the precipitation of disordered dolomite/dolomite in modern settings and geological records.

This work was financially supported by the Natural Science Foundation of China (Nos. 41572026 and 41772030). 